\title{
The Response of Equatorial Waves to Thermal Forcing
}

\author{
By Hisanori Itoh* \\ Geophysical Institute, Kyoto University, Kyoto 606, Japan \\ (Manuscript received 25 October 1976, in revised form 10 March 1977)
}

\begin{abstract}
The response of the stratospheric equatorial waves to thermal forcing is theoretically discussed, taking into account various factors such as the meridional distribution of heating and the vertical shear of the mean zonal wind. First we discuss analytically these effects based on normal mode models and then we treat a realistic three-dimensional model by numerical method.

The horizontal structure of waves obtained in the models including the above effects indicates that the dominant wave modes are identified as Kelvin waves, mixed Rossby-gravity waves and $n=1$ Rossby waves, and that gravity waves are not prominent. The coexistence of gravity waves with the dominant modes, however, in the realistic model with maximum heating near the ITCZ makes the heating and vertical motion to be in phase, in agreement with observations, while in the single-component normal mode model they are in quadrature. It is concluded that mixed Rossby-gravity waves have the maximum response at wavenumbers 4-5 as observed, in view of the effect of vertical shear of the mean zonal wind on the selectivity of wavenumbers.

In normal mode mcdels hitherto treated the vertical wavelength of the dominant waves (resonant waves) was somewhat longer and hence the period was shorter, compared with observations. The defect still remains in the present model, though improved to some extent by introducing the realistic distribution of heating. Vertical structure of wind and temperature for predominant waves also shows different features from observed ones in the troposphere.

Although some characteristics of observed equatorial waves are accounted for in light of the present model, these results suggest that the observed waves cannot be interpreted merely as the resonant waves by thermal forcing.
\end{abstract}

\section{Introduction}

Since the theoretical studies on the nature of equatorial waves by Rosenthal (1965) and Matsuno (1966), it has been known that there are Rossby type waves, gravity type waves and hybrid modes (eastward-moving Kelvin wave and westward-moving mixed Rossby-gravity wave) as equatorial normal modes. Extension of the equatorial wave theory was made by Lindzen (1967) to the three-dimensional structure and vertical propagatability by considering the vertical structure equation.

Meanwhile many observational studies of the stratospheric wave disturbances showed that among these possible waves only wave modes with particular wavenumbers and frequencies are

\footnotetext{
* Present affiliation: Department of Earth Sciences, Faculty of Education Wakayama University, Wakayama
}

found in the actual atmosphere. Mixed Rossbygravity waves of wavenumbers 3-4 (s=3-4) and periods 4-5 days ( $T=4-5$ days) were discovered by Yanai and Maruyama (1966) and Maruyama (1967), and Kelvin waves of $s=1-2, T=8-20$ days by Wallace and Kousky (1968). Recently the existence of $n=1$ Rossby waves with $s=1-2$, $T=7-10$ days was reported by Odo (1976). From the analyses of general circulation model products by Hayashi (1974) and Tsay (1974), similar predominance of wavenumber and period is found.

Then a question arises as to what causes such selectivity for wavenumbers and periods. The vertical structure of the predominant waves may be one of the important aspects by which we can gain an insight into the origin of the waves; westward-moving mixed Rossby-gravity waves tilt westward with increasing height and eastwardmoving Kelvin waves tilt eastward in the upper 
troposphere and in the stratosphere. Lindzen and Matsuno (1968) showed that the downward phase propagation implies an upward propagation of wave energy, so that these waves are not generated in the stratosphere but in the troposphere, and propagate into the stratosphere. Therefore, there can be two standpoints to explain the dominant waves in the stratosphere. One is to explain them as the result of selectivity in wave generation in the troposphere and the other is as the result of selectivity in the course of wave propagation. The wavenumbers and periods of the dominant waves in the stratosphere are also found in the tropospheric waves, although it seems that the most dominant wavenumbers in the tropospheric mixed Rossby-gravity waves are 4-5 with slight difference from those in the stratospheric ones (3-4) (e.g., Nitta, 1972). Thus, it seems more reasonable to consider the predominance of the equatorial waves in the stratosphere as the result of the selectivity in wave generation.

There have been three approaches to explain the excitation and selection of these waves. The first approach is a theory of resonance to midlatitude forcing. According to Mak (1969) and Lamb (1973), the tropical atmosphere has a resonant periods of 4-5 days and a resonant wavenumber 4 to mid-latitude forcing. However, Hayashi (1976) showed that the latitudinal structure of the dominant waves much differs from observations. It is also questionable whether a vertical wavelength of mid-latitude forcing can be given arbitrarity.

The second approach is based on the so-called wave-CISK theory which deals with the instability property of waves by cumulus heating organized by waves themselves. Hayashi (1970) showed that both mixed Rossby-gravity wave with $s=4$, $T=4$ days and Kelvin wave with $s=1, T=15$ days become unstable and that the vertical structure of unstable waves coincides well with that of the observed waves. However, the modes with maximum growth rate are gravity waves of large wavenumbers with high frequencies, and mixed Rossby-gravity waves and Kelvin waves are not most unstable at their observed wavenumbers. Recently Kuo (1975) re-examined the wave-CISK theory by considering the moisture supply efficiency depending on wave frequency. According to his results, gravity wave modes are no longer unstable and the most unstable waves appear at wavenumber 4 for both mixed Rossbygravity wave and Kelvin wave with periods of 5 and 6 days, respectively.

The third approach to account for the wave generation is to investigate the response of the tropical atmosphere to thermal forcing due to cumulus convection. Holton (1972) studied the selectivity of antisymmetric mode, assuming a 5-day standing oscillation of heating over the ITCZ. According to his model with an easterly shear flow, westward-moving mixed Rossbygravity waves with $s=3-4$ are selected in the stratosphere. Holton (1973) also found that, for white noise symmetric heating, Kelvin waves with $s=1, T=10-20$ days and with $s=2, T=5-10$ days have a maximum response. However, as both the wave selection in the course of the wave propagation in a shear flow and the response characteristics to forcing are included simultaneously, each property cannot be understood clearly. Very recently, Hayashi (1976) studied the resonance of equatorial waves to a thermal forcing based on the idea of the selectivity for wave generation. He showed that a "non-singular resonance" occurs under the radiation condition when the vertical scale of a wave (half vertical wavelength) in a free isothermal atmosphere coincides with that of thermal forcing. But he concluded that it is difficult to interpret the observed Yanai-Maruyama waves as resonant waves. The reasons are that 1) the vertical wavelength is longer, so the resonant period is shorter than the observed ones; 2) the heating is nearly in quadrature with the vertical motion contrary to the observed in-phase relation; 3) maximum response of mixed Rossby-gravity wave appears at large wavenumbers. The items 1) and 2) are also the case in the resonant Kelvin waves.

The main object of the present paper is, despite of Hayashi's results, to re-examine possibility of the equatorial wave excitation due to thermal effect. Special emphasis will be put on the following effects which were not taken by Hayashi; 1) the vertical profile of thermal forcing, 2) the meridional distribution of thermal forcing and 3) the vertical shear of the mean zonal wind. We shall first study the response properties by the normal mode models in Section 2 and then advance to the realistic three-dimensional model in Section 3.

\section{Normal mode models}

\section{2-1. Basic equations and solutions}

The linearized equations of zonal momentum, meridional momentum, hydrostatics, continuity and thermodynamics without basic flow on equa- 
torial beta-plane are written as follows:

$$
\begin{aligned}
& \frac{\partial u^{\prime}}{\partial t}-\beta y v^{\prime}=-\frac{\partial \Phi^{\prime}}{\partial x}-D u^{\prime}, \\
& \frac{\partial v^{\prime}}{\partial t}+\beta y u^{\prime}=-\frac{\partial \Phi^{\prime}}{\partial y}-D v^{\prime}, \\
& \frac{\partial \Phi^{\prime}}{\partial z}=\frac{R}{H} T^{\prime}, \\
& \frac{\partial u^{\prime}}{\partial x}+\frac{\partial v^{\prime}}{\partial y}+\frac{\partial w^{\prime}}{\partial z}-\frac{w^{\prime}}{H}=0, \\
& \frac{\partial T^{\prime}}{\partial t}+S w^{\prime}=\frac{Q^{\prime}}{c_{p}}-D T^{\prime},
\end{aligned}
$$

where the vertical coordinate is logarithmic pressure $\left(z \equiv-H \ln P / P_{0}\right)$. Symbols are defined in an appendix. We shall separate the time and space variables by assuming the following form as solutions:

$$
\left[\begin{array}{l}
u^{\prime} \\
v^{\prime} \\
\Phi^{\prime} \\
w^{\prime} \\
T^{\prime} \\
Q^{\prime}
\end{array}\right]=\left(\begin{array}{l}
\frac{g h}{i \hat{\omega}} u(y)\left(\frac{d w(z)}{d z}-\frac{w(z)}{2 H}\right) \\
\frac{g h}{i \hat{\omega}} v(y)\left(\frac{d w(z)}{d z}-\frac{w(z)}{2 H}\right) \\
\frac{g h}{i \hat{\omega}} \Phi(y)\left(\frac{d w(z)}{d z}-\frac{w(z)}{2 H}\right) \\
\Phi(y) w(z) \\
\frac{g h}{i \widehat{\omega}} \frac{H}{R} \Phi(y)\left(\frac{d^{2} w(z)}{d z^{2}}-\frac{w(z)}{4 H^{2}}\right) \\
\Phi(y) Q(z)
\end{array}\right) e^{z / 2 H} e^{i(\omega t+k x)}
$$

where $\hat{\omega}=\omega-i D$. If we assume a constant basic flow, $\bar{u}$, the following treatments will be made similarly by replacing $\widehat{\omega}$ by $\omega+k \bar{u}-i D$. By substitution of (6)-(11) into (1)-(5) and after manupulation we get the horizontal structure equation (12) and vertical structure equation (13).

$$
\begin{aligned}
& {\left[\begin{array}{ccr}
i \hat{\omega} & -\beta y & i k \\
\beta y & i \widehat{\omega} & \frac{d}{d y} \\
i k & \frac{d}{d y} & \frac{i \widehat{\omega}}{g h}
\end{array}\right)\left(\begin{array}{l}
u(y) \\
v(y) \\
\Phi(y)
\end{array}\right)=0} \\
& \frac{d^{2} w(z)}{d z^{2}}+\left(\frac{S R}{g h H}-\frac{1}{4 H^{2}}\right) w(z)=\frac{R}{g h H} \frac{Q(z)}{c_{p}}
\end{aligned}
$$

The boundary conditions are

$$
\begin{array}{lll}
u(y), \quad v(y), \quad \Phi(y) \rightarrow 0 & \text { as } & y \rightarrow \pm \infty, \\
w=0 & \text { at } & z=0, \\
\frac{d w}{d z}=i \lambda w & &
\end{array}
$$

$$
\lambda^{2} \equiv \frac{S R}{g h H}-\frac{1}{4 H^{2}} .
$$

Eq. (15) is only approximate (see Holton, 1975). Eq. (16) is the radiation condition applied at the level above which the static stability $S$ is constant and $Q(z)=0$. As the resonant waves for external free oscillation and the other external waves are not dominant in the stratosphere over the equator, we take only the case of $\operatorname{Re}\left(\lambda^{2}\right)>0$ where $R e$ represents real part of the quantity in the parenthesis. Thus, in the case of eastwardmoving waves $\operatorname{Re}(\lambda)<0$ is adopted; westwardmoving waves $\operatorname{Re}(\lambda)>0$.

Here we consider forced wave only, so that the solutions are obtained in the following way: First, from the horizontal structure equation we get the eigenvalue $h$ and the eigensolutions $u, v, \Phi$ for given values of $\omega$ and $k$. Next, we obtain the solutions $w$ of the vertical structure equation corresponding to the eigenvalue $h$, and then, by substituting $\omega, k, h, u, v, \Phi, w$ into Eqs. (6)-(10), we have a complete set of solutions.

The eigenvalues and eigensolutions have been derived by Matsuno (1966), Lindzen (1967), Lindzen and Matsuno (1968) and Holton and Lindzen (1968). The eigenvalues of the equatorial normal modes are given by

$$
\begin{aligned}
\sqrt{g h_{n}}= & \frac{(2 n+1) \Omega}{k\left(\frac{2 \Omega}{\widehat{\omega}}-k a\right)}\left[1 \pm\left\{1-\left(\frac{\widehat{\omega}}{\Omega}\right)^{2} \frac{k a}{(2 n+1)^{2}}\right.\right. \\
& \left.\left.\cdot\left(\frac{2 \Omega}{\widehat{\omega}}-k a\right)\right\}^{1 / 2}\right](n=1,2, \cdots) \quad(18)
\end{aligned}
$$

where positive sign corresponds to an internal Rossby mode and negative sign an internal gravity wave mode. For mixed Rossby-gravity wave $(n=0)$ and Kelvin wave $(n=-1)$, the equivalent depth $h$ is given by

$$
\sqrt{g} \overline{h_{0}}=\frac{\hat{\omega}}{\frac{2 \Omega}{\hat{\omega} a}-k},
$$

and

$$
\sqrt{g \bar{g}} \overline{-1}=-\frac{\widehat{\omega}}{k},
$$

respectively. The eigensolutions are given by

$$
\begin{aligned}
& v_{n}(y)=H_{n}\left(\varepsilon_{n}^{1 / 2} y\right) \exp \left[-\frac{\varepsilon_{n}}{2} y^{2}\right] \\
& u_{n}(y)=-\frac{i\left(g h_{n} \varepsilon_{n}\right)^{1 / 2}}{\widehat{\omega}}\left\{\frac{n H_{n-1}\left(\varepsilon_{n}^{1 / 2} y\right)}{1-\frac{k}{\widehat{\omega}} \sqrt{g h_{n}}}\right.
\end{aligned}
$$

where 


$$
\begin{gathered}
\left.+\frac{(1 / 2) H_{n+1}\left(\varepsilon_{n}^{1 / 2} y\right)}{1+\frac{k}{\widehat{\omega}} \sqrt{g h_{n}}}\right\} \exp \left[-\frac{\varepsilon_{n}}{2} y^{2}\right] \\
\Phi_{n}(y)=\frac{i g h_{n} \varepsilon_{n}^{1 / 2}}{\widehat{\omega}}\left\{\frac{n H_{n-1}\left(\varepsilon_{n}^{1 / 2} y\right)}{1-\frac{k}{\widehat{\omega}} \sqrt{g h_{n}}}\right. \\
\left.-\frac{(1 / 2) H_{n+1}\left(\varepsilon_{n}^{1 / 2} y\right)}{1+\frac{k}{\widehat{\omega}} \sqrt{g h_{n}}}\right\} \exp \left[-\frac{\varepsilon_{n}}{2} y^{2}\right] \\
(n=0,1,2, \ldots)
\end{gathered}
$$

where $H n(y)$ is Hermite's polynomials (assuming $\left.H_{-1}=0\right)$ and

$$
\varepsilon_{n} \equiv \frac{\beta}{\sqrt{g h_{n}}} .
$$

For Kelvin wave, we have

$$
\begin{aligned}
& v_{-1}(y)=0, \\
& u_{-1}(y)=\exp \left[-\frac{\varepsilon_{-1}}{2} y^{2}\right], \\
& \Phi_{-1}(y)=\sqrt{g h_{-1}} \exp \left[-\frac{\varepsilon_{-1}}{2} y^{2}\right] .
\end{aligned}
$$

It is seen from Eqs. (6)-(11) that the smaller $\hat{\omega}$ is, the larger $u^{\prime}, v^{\prime}, \Phi^{\prime}$ and $T^{\prime}$ are (except $w^{\prime}$ ) if. $\omega \ll D$ and other things are unchanged. Therefore, waves of the longest period are selected for fixed values of $h$ and $Q$. In this sense we can expect that the dominant waves are wavenumber 1 for Kelvin waves and $n=1$ Rossby waves and large wavenumbers for mixed Rossby-gravity waves. Also we can anticipate that gravity waves are not dominant since their periods are too short.

Regarding the thermal forcing, we assume

$$
Q(z)= \begin{cases}Q_{0} e^{\gamma z} \sin \frac{\pi}{z_{t}} z & \text { for } \quad 0 \leq z \leq z_{t} \\ 0 & \text { for } z>z_{t}\end{cases}
$$

Note that a factor $e^{r z}$ is included in the expression of our heat source and hence the maximum of heating is situated at various levels by the variation of $\gamma$. Hereafter we take $z_{t}=14 \mathrm{~km}$ except subsection 2-2 and $\gamma=0$ except subsection 2-3.

If we assume an isothermal atmosphere, the solution of Eq. (13) is obtained, in a similar manner to Lindzen's one (1974), as follows:

$$
\begin{gathered}
w_{1}(z)=\frac{\kappa}{g h H} Q_{0}\left[-\frac{\sin \lambda z}{\lambda} \frac{1}{(\gamma+i \lambda)^{2}+M^{2}}\right. \\
\times\left\{M\left(e^{(\gamma+i \lambda) z t}+e^{(\gamma+i \lambda) z} \cos M z\right)\right.
\end{gathered}
$$

$$
\begin{aligned}
& \left.-(\gamma+i \lambda) e^{(\gamma+i \lambda) z} \cdot \sin M z\right\} \\
& +\frac{e^{i \lambda z}}{2 \lambda}\left\{\frac { 1 } { ( M + \lambda ) ^ { 2 } + \gamma ^ { 2 } } \left[\gamma\left(e^{\gamma z} \cos (M+\lambda) z-1\right)\right.\right. \\
& \left.+(M+\lambda) e^{\gamma z} \sin (M+\lambda) z\right] \\
& -\frac{1}{(M-\lambda)^{2}+\gamma^{2}}\left[\gamma\left(e^{\gamma z} \cos (M-\lambda) z-1\right)\right. \\
& \left.\left.\left.+(M-\lambda) e^{\gamma z} \sin (M-\lambda) z\right]\right\}\right] \\
& \text { for } 0 \leq z \leq z_{t}, \\
& \times\left[\gamma\left(-e^{\gamma z t} \cos \lambda z_{t}-1\right)-(M+\lambda) e^{\gamma z_{t}} \sin \lambda z_{t}\right] \\
& -\frac{1}{(M-\lambda)^{2}+\gamma^{2}}\left[\gamma\left(-e^{\gamma z t} \cos \lambda z_{t}-1\right)\right. \\
& \left.\left.+(M-\lambda) e^{\gamma z t} \sin \lambda z_{t}\right]\right\} \quad \text { for } z>z_{t}, \quad(29)
\end{aligned}
$$

where $M=\pi / z_{t}$. Setting $\gamma=0$, we have

$$
\begin{aligned}
& w_{1}(z)=\frac{\kappa}{g h H} Q_{0} \frac{1}{\lambda^{2}-M^{2}} \\
& \times\left\{\frac{M}{\lambda\left(\cos \lambda z_{t}-i \sin \lambda z_{t}\right)} \sin \lambda z+\sin M z\right\} \\
& \text { for } 0 \leq z \leq z_{t}, \\
& w_{2}(z)=\frac{\kappa}{g h H} Q_{0} \frac{1}{\lambda^{2}-M^{2}} \\
& \times \frac{M \sin \lambda z_{t}}{\lambda\left(\cos \lambda z_{t}-i \sin \lambda z_{t}\right)} e^{i \lambda\left(z-z_{t}\right)} \\
& \text { for } z>z_{t} .
\end{aligned}
$$

The solution (30) and (31) is identical to that by Hayashi (1976). When $\lambda=M$, i.e., when the socalled non-singular resonance discussed by $\mathrm{Ha}-$ yashi (1976) occurs, we have

$$
\begin{aligned}
& w_{1}(z)=\frac{\kappa}{g h H} Q_{0} \frac{1}{2 M} \\
& \times\left\{\left(\frac{1}{M}-i \frac{\pi}{M}\right) \sin M z-z \cos M z\right\} \\
& \text { for } 0 \leq z \leq z_{t}, \\
& w_{2}(z)=\frac{\kappa}{g h H} Q_{0} \frac{z_{t}}{2 M} e^{i \lambda\left(z-z_{t}\right)} \\
& \text { for } z>z_{t} .
\end{aligned}
$$

Hereafter we discuss the selectivity of the wave perturbation in terms of $u^{\prime}$ for Kelvin waves and $n=1$ Rossby waves and in terms of $v^{\prime}$ for mixed Rossby-gravity waves over the equator.

\section{2-2. Dependency on the vertical scale of heating}

Hayashi (1976) showed that the maximum re- 
sponse occurs at $\lambda \sim M$ taking a particular value $(=10 \mathrm{~km})$ as $z_{t}$. For Kelvin waves, using $u_{-1}$ $(0)=1$,

$$
\begin{aligned}
\left|u^{\prime}\right|= & \left(\frac{\kappa}{g h}\right)^{1 / 2} \frac{a}{s} Q_{0} \frac{M}{\lambda}\left\{\left(\frac{\lambda}{M}\right)^{2}+\frac{1}{4 H^{2} M^{2}}\right\} \\
& \times\left|\frac{\sin \pi \frac{\lambda}{M}}{\left(\frac{\lambda}{M}\right)^{2}-1}\right|
\end{aligned}
$$

where a factor $e^{z / 2 H}$ is omitted (hereafter in the same manner in Section 2). For mixed Rossbygravity waves, using $v_{0}(0)=1$,

$$
\begin{aligned}
\left|v^{\prime}\right| & =\left(\frac{k}{g H}\right)^{1 / 2} a Q_{0}\left(-\frac{S}{2}\right. \\
& \left.+\sqrt{\left(\frac{S}{2}\right)^{2}+\beta a^{2}\left(\frac{H}{k g}\right)^{1 / 2}\left(\lambda^{2}+\frac{1}{4 H^{2}}\right)^{1 / 2}}\right)^{-1} \\
& \times \frac{M}{\lambda}\left\{\left(\frac{\lambda}{M}\right)^{2}+\frac{1}{4 H^{2} M^{2}}\right\}\left|\frac{\sin \pi \frac{\lambda}{M}}{\left(\frac{\lambda}{M}\right)^{2}-1}\right| .
\end{aligned}
$$

Since for waves of our interest $\lambda$ and $M \gg 1 / 2 H$, in the right hand side of (34) and (35), $\lambda$ and $M$ appear mainly in the form of $\lambda / M$. Therefore, we can say that the Hayashi's argument remains correct even if the vertical scale of heating $\left(z_{t}\right)$ is changed.

The phase difference $\theta$ between $Q^{\prime}$ and $w^{\prime}$ at the level where $Q(z)$ is maximum (hereafter referred to as $z_{\max }$ ) is obtained by using (27) and (30) as following,

$$
\theta=\left\{\begin{array}{rr}
\tan ^{-1}\left\{\left(-\frac{M}{\lambda} \sin \lambda_{t} z \sin \lambda \frac{z_{t}}{2}\right) \mid\right. \\
\left.\left(\frac{M}{\lambda} \cos \lambda z_{t} \sin \lambda \frac{z_{t}}{2}+1\right)\right\} \\
\tan ^{-1} \pi & \text { for } \lambda \neq M,
\end{array}\right.
$$

Thus, when $\lambda \sim M$, the phase relationship between $Q^{\prime}$ and $w^{\prime}$ becomes in quadrature in the troposphere in agreement with the Hayashi's conclusion.

\section{2-3. Dependency on the vertical distribution of heating}

In this subsection how the wave properties vary with $z_{\max }$ is discussed. As seen in Eq. (27), the variation of $z_{\max }$ is determined by that of $\gamma$. We assume an isothermal atmosphere and $D=0$. Heating amplitude is normalized in such a way that $\int_{0}^{z_{t}} e^{-z / H} Q(Z)$ and $\left[\int_{0}^{\infty} \Phi_{n}{ }^{2}(y) d y\right]^{1: 2}$ are

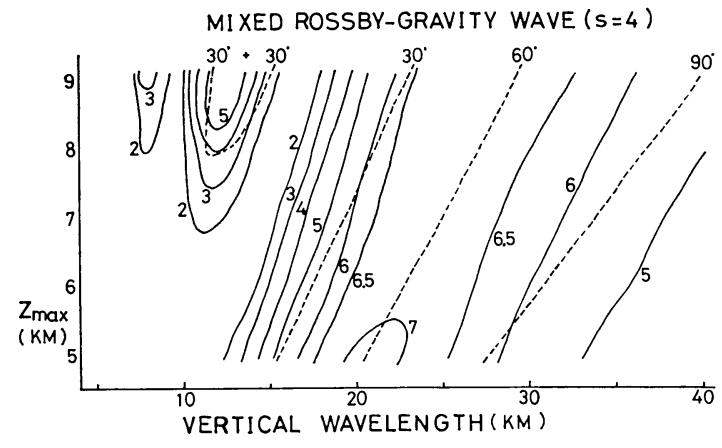

Fig. 1 Amplitude of meridional wind component at $z=z_{t}$ over the equator $(\mathrm{m} / \mathrm{sec}$, solid line) and phase difference between $Q^{\prime}$ and $\boldsymbol{w}^{\prime}$ at $z=\boldsymbol{z}_{\max }$ (dashed line) for mixed Rossby-gravity waves of $s=4$ as a function of vertical wavelength and $z_{\max }$ in the isothermal model.

constants (Regarding the normalization factors, see 2-5). Fig. 1 shows amplitude and phase difference between $Q^{\prime}$ and $w^{\prime}$ at $z_{\max }$ for mixed Rossby-gravity waves of wavenumber 4 obtained from Eqs. (28), (29) and (6). The greatest peak of $v^{\prime}$ exists at $\lambda \sim M$ (corresponding to vertical wavelength of $28 \mathrm{~km}$ ) similar to the case of $z_{\max }=z_{t} / 2 \quad(\gamma=0)$, with nearly in quadrature phase relation between $Q^{\prime}$ and $w^{\prime}$. When $z_{\max }$ becomes greater than $z_{t} / 2$, the second peak appears at $\lambda \sim 2 M$ (corresponding to vertical wavelength of $14 \mathrm{~km}$ ). This may be interpreted as the effect of bi-mode of the forcing.

Since $z_{\max } \sim z_{t} / 2$ in the actual atmosphere as shown by Reed and Recker (1971) and others, it may not be adequate to assume the vertical distribution of forcing arbitrarily. Anyway the phase relation of the waves with maximum amplitude is not so sensitive to vertical profile of forcing.

\section{2-4. Effect of the variation of static stability (model S)}

In the results obtained in the previous subsections the resonant vertical wavelength was considerably longer, so that the resonant periods were shorter than the observed ones. This is mainly due to the crude assumption of an isothermal atmosphere. If we assume a smaller value as the static stability in the troposphere, we find from Eq. (17) that the resonant equivalent depth becomes small because the resonant vertical wavelength in the troposphere must be the same. Therefore, the resonant periods become longer as seen from the dispersion relation (18), (19) and 
(20), and the vertical wavelength in the stratosphere tends to be shorter owing to the larger stability there.

In order to estimate this effect quantitatively, we derive the vertical structure equation for a two-layer model. Assuming that the stratosphere is isothermal and that the stability in the troposphere is $S_{1}$, we obtain

$$
\begin{aligned}
& \frac{d^{2} w_{1}}{d z^{2}}+\lambda_{1}{ }^{2} w_{1}=f_{h} \sin M z \text { for } 0<z<z_{t}, \\
& \frac{d^{2} w_{2}}{d z^{2}}+\lambda_{2}{ }^{2} w_{2}=0 \quad \text { for } z>z_{t},
\end{aligned}
$$

where

$$
\begin{aligned}
& \lambda_{1}{ }^{2} \equiv \frac{S_{1} R}{g h H}-\frac{1}{4 H^{2}}, \\
& \lambda_{2}{ }^{2} \equiv \frac{\kappa}{h H}-\frac{1}{4 H^{2}}, \\
& f_{h} \equiv \frac{\kappa}{g h H} Q_{0} .
\end{aligned}
$$

The solution of these equations is

$$
\begin{aligned}
w_{1}(z) & =\frac{f_{h}}{\lambda_{1}{ }^{2}-M^{2}} \\
\times & {\left[\frac{M}{\lambda_{1} \cos \lambda_{1} z_{t}-i \lambda_{2} \sin \lambda_{1} z_{t}} \sin \lambda_{1} z\right.} \\
+ & \sin M z], \\
w_{2}(z) & =\frac{f_{h}}{\lambda_{1}{ }^{2}-M^{2}} \\
\times & \frac{M \sin \lambda z_{t}}{\lambda_{1} \cos \lambda_{1} z_{t}-i \lambda_{2} \sin \lambda_{1} z_{t}} e^{i \lambda_{2}\left(z-z_{t}\right)} .
\end{aligned}
$$

When $\lambda_{1}=M$,

$$
\begin{aligned}
& w_{1}(z)=\frac{f_{h}}{2 M}\left[\left(\frac{1}{M}-i \frac{\lambda_{2} z_{t}}{M}\right) \sin M z-z \cos M z\right] \\
& w_{2}(z)=\frac{f_{h}}{2 M} z_{t} e^{i \lambda_{2}\left(z-z_{t}\right)}
\end{aligned}
$$

Fig. 2 shows the amplitude (middle) and phase (lower) of mixed Rossby-gravity waves $(s=4)$ when $\lambda_{1}=0.5 \lambda_{2}$ (the static stability in the troposphere is about a quarter of that in the stratosphere), and the projection coefficient* of forcing (upper) as function of vertical wavelength.

* Fourier expansion of the forcing defined in (27) on vertical wavelength. The projection coefficient of vertical wavenumber $\lambda$ is $Q_{0} \sin \lambda z_{t} /[\pi\{1-$ $\left.\left(\lambda z_{t} / \pi\right)^{2}\right\}$ ] for $\lambda \neq(\pi / z t)$ and $\left(Q_{0} / 2\right)$ for $\left(\pi / z_{t}\right)$ in this case, where $Q_{0}$ is not a constant but a function of $\lambda$, since the heating amplitude is normalized.

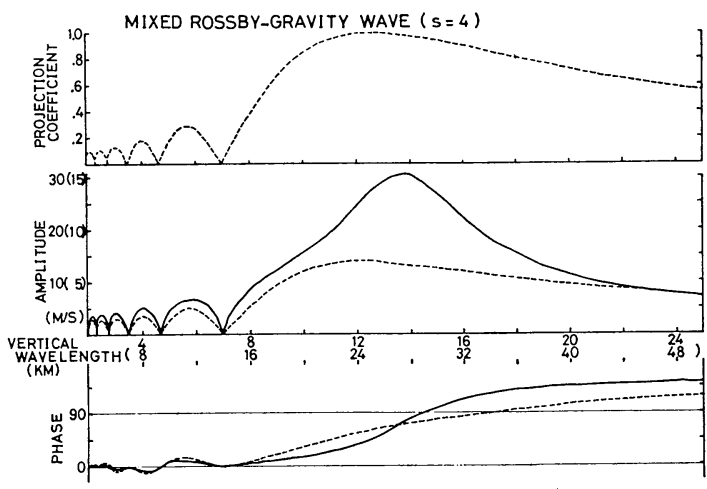

Fig. 2 Projection coefficient of forcing on various vertical modes (normalized by its maximum) [upper], amplitude of meridional wind component $(\mathrm{m} / \mathrm{sec})$ at $z=z_{t}$ over the equator [middle] and phase difference between $Q^{\prime}$ and $w^{\prime}$ at $z=z_{t} / 2$ [lower] for mixed Rossbygravity waves of $s=4$ in the model $S$ (solid line) and the isothermal model (dashed line) as a function of 'vertical wavelength in the stratosphere. Values in the parenthesis are used for the isothermal model.

Results for the isothermal atmosphere are also inserted by dashed lines. The vertical wavelength of the resonant wave in the stratosphere is reduced to a half of that in the troposphere and the period becomes longer compared with the case of the isothermal atmosphere. As $f_{h}=Q_{o} / g$ $\left(\lambda_{2}{ }^{2}+1 / 4 H^{2}\right), w$-amplitude becomes larger on the whole, owing to the increase of $\lambda_{2}$, and wind amplitudes also become larger because $u^{\prime} v^{\prime}$ $\propto(h / \hat{\omega})\left(i \lambda_{2}-1 / 2 H\right) w$. However, the imaginary part of the denominator in (41) and (42) i.e., $\lambda_{2} \sin \lambda_{1} z_{t}$, dominates unless $\sin \lambda_{1} z_{t}$ is near zero (if the vertical wavenumber $\lambda_{1}$ is not nearly equal to $M, 2 M,---)$, so it makes the amplitude relatively small. Ultimately the variation of the static stability has an effect to intensify the so-called non-singular resonance and to make the peak sharper with respect to vertical wavelength. This is because the partical reflection of the wave with non-singular resonance takes place by the presence of the discontinuity of the static stability and consequently (weak) resonance in ordinary sense is realized. The phase relationship between $Q^{\prime}$ and $w^{\prime}$ shows a tendency to have a discontinuous change at the resonance wavelength, and is as a matter of course. These effects may be retained when the stability varies continuously.

We can also find from this figure that the wave 
amplitude is closely related to the projection coefficient of forcing, especially in the isothermal model. Thus the fact that the vertical wavelength of maximum amplitude increases with $z_{\max }$ as shown in Fig. 1, is explained as the result of shift of the wavelength of maximum projection coefficient.

\section{2-5. Influence of the meridional distribution of thermal forcing}

Although we have hitherto assumed that the meridional distribution of $Q^{\prime}$ coincides with the eigenfunction of $\Phi^{\prime}$, the real distribution of heating is independent of wave modes and has its maximum in the region of the ITCZ. This fact may be related to the sea surface temperature which is primarily independent of the atmospheric wave motion. Therefore, it will be reasonable for us to investigate the response of waves to the forcing which has the maximum amplitude at the ITCZ.

We give the distribution of forcing by

$$
Q^{\prime}=Q(z) q(y) e^{z / 2 H} e^{i(\omega t+k x)},
$$

where

$$
q(y)= \begin{cases}\frac{A y}{y_{0}} \exp \left[-\frac{y^{2}}{2 y_{0}^{2}}+\frac{1}{2}\right] \begin{array}{l}
\text { for antisymmetric } \\
\text { modes }
\end{array} \\
\frac{A|y|}{y_{0}} \exp \left[-\frac{y^{2}}{2 y_{0}^{2}}+\frac{1}{2}\right] \begin{array}{l}
\text { for symmetric } \\
\text { modes. }
\end{array}\end{cases}
$$

A is a constant whose dimension is length/time. In the present study we define symmetric and antisymmetric modes not with $v^{\prime}$ but with $u^{\prime}$ or $\Phi^{\prime}$. Note that $q(y)$ takes a maximum at $y= \pm y_{0}$. We take $Q(z)=Q_{0} \sin \left(\pi / z_{t}\right) z, Q_{0} A / C_{p}=3^{\circ} \mathrm{K} /$ day and $y_{0}=600 \mathrm{~km}$. This heating function (45) was used in 2-3 for normalization of heating amplitude.

First we define the following quantity;

$$
a_{n}=\int_{0}^{\infty} q_{N}(y) \Phi_{n N}(y) d y
$$

where suffix $N$ indicates that $q$ and $\Phi_{n}$ are normalized. This quantity represents the projection of the realistic heating onto a normal mode $\Phi_{n}$, since $\Phi_{n}$ 's are orthogonal when $\omega$ is fixed and $h_{n}$ is an eigenvalue. Thus the amplitude of a normal mode in the case of the realistic meridional distribution of heating (denoted RA) is obtained by multiplying horizontal projection coefficient $a_{n}$, by the wave amplitude in the case that the latitudinal distribution of $Q^{\prime}$ is $\Phi_{n}(y)$ (denoted SA). For the first three latitudinal mode in which we are most interested, $a_{n}$ 's are given as

$$
\begin{aligned}
a_{-1}= & \frac{2 \sqrt{2} \varepsilon_{-1}{ }^{1 / 4}}{\sqrt{\pi} y_{0}^{3 / 2}\left(\frac{1}{y_{0}^{2}}+\varepsilon_{-1}\right)}, \\
a_{0}= & \frac{2 \sqrt{2} \varepsilon_{0}^{3 / 4}}{y_{0}^{3 / 2}\left(\frac{1}{y_{0}^{2}}+\varepsilon_{0}\right)^{3 / 2}}, \\
a_{1}= & \frac{2 \sqrt{2} \varepsilon_{1}^{1 / 4}}{\sqrt{\pi} y_{0}^{3 / 2}\left(\frac{1}{y_{0}^{2}}+\varepsilon_{1}\right)^{2}} \\
& \times \frac{\left(1+\frac{k}{\hat{\omega}} \sqrt{g h_{1}}\right)\left(\frac{1}{y_{0}^{2}}-\varepsilon_{1}+2 \frac{k}{\hat{\omega}} \sqrt{g} h_{1} \varepsilon_{1}\right)}{\left\{\frac{3}{4}+\frac{k}{\hat{\omega}} \sqrt{g h_{1}}+\frac{1}{2}\left(\frac{k}{\hat{\omega}} \sqrt{g} \overline{h_{1}}\right)^{2}\right.} \\
& \left.\quad+\left(\frac{k}{\hat{\omega}} \sqrt{g h_{1}}\right)^{3}+\frac{3}{4}\left(\frac{k}{\widehat{\omega}} \sqrt{g} h_{1}\right)^{4}\right\}^{1 / 2},
\end{aligned}
$$

using the following relations,

$$
\begin{aligned}
& \int_{0}^{\infty} e^{-\alpha x^{2}} d x=\frac{1}{2} \sqrt{\frac{\pi}{\alpha}}, \\
& \int_{0}^{\infty} e^{-\alpha x^{2}} x^{2 n} d x=\frac{(2 n-1) ! !}{2^{n+1}} \sqrt{\frac{\pi}{\alpha^{2 n+1}}}, \\
& \int_{0}^{\infty} e^{-\alpha x^{2}} x^{2 n+1} d x=\frac{n !}{2 \alpha^{n+1}},
\end{aligned}
$$

where $(2 n-1) ! !=(2 n-1) \cdot(2 n-3)---3 \cdot 1$.

Fig. 3 shows $a_{n}$, SA, RA and phase difference between $Q^{\prime}$ and $w^{\prime}$ for Kelvin wave $(s=1)$ and mixed Rossby-gravity wave $(s=4)$ as functions of vertical wavelength in the model $S\left(\lambda_{1}=0.5 \lambda_{2}\right)$. As $a_{n}$ decreases with increasing vertical wavelength in the vicinity of non-singular resonance mode, the peak of each wave mode shifts toward short vertical wavelength when the realistic horizontal distribution of $Q^{\prime}$ is taken into account. Consequently the period of maximum response becomes longer and the phase difference of $Q^{\prime}$ and $w^{\prime}$ shifts from $90^{\circ}$ to $0^{\circ}$. However, the changes are too small to explain the observed characteristics of waves. This is also the case, even if we assume the continuous distribution of static stability and the variation of $y_{0}$.

\section{2-6. Selectivity for periods and wavenumbers}

Fig. 4 shows perturbation wave amplitude RA at the level $z_{t}$ for Kelvin waves, mixed Rossbygravity waves and $n=1$ Rossby waves as functions of period and wavenumber. The vertical profile of static stability is the same as model $S$ $\left(S_{1}=g / 4 c_{p}\right)$ and a damping of $D=1 / 15$ days is included. For Kelvin waves, it seems that the selectivity for periods and wavenumbers agrees well with observations. The selected width is broad for periods and rather narrow for wave- 

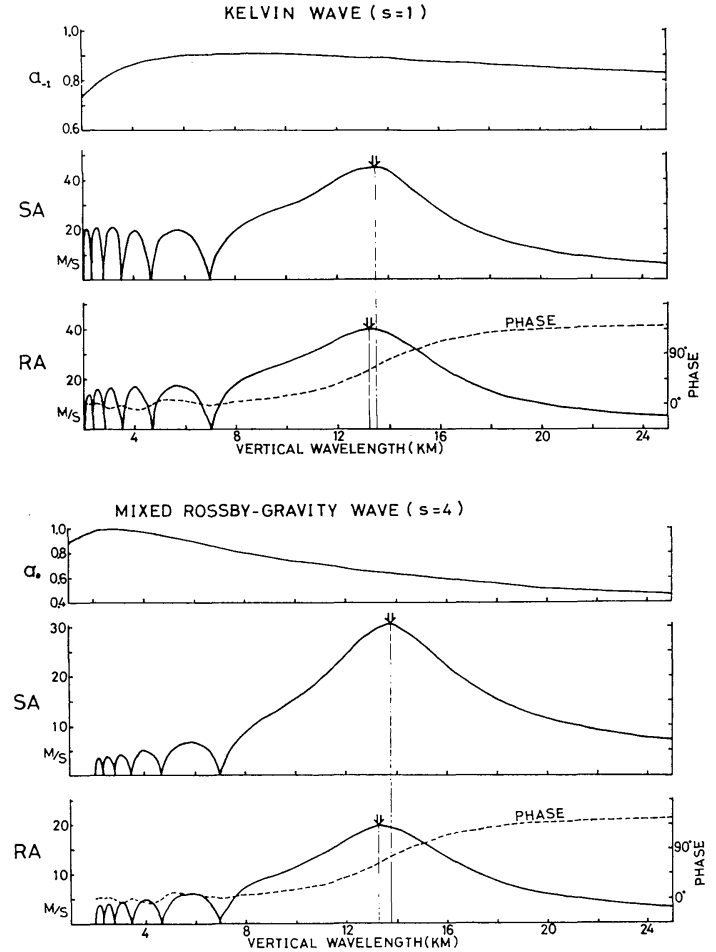

Fig. $3 a_{n}, \mathrm{SA}(\mathrm{m} / \mathrm{sec}), \quad \mathrm{RA}(\mathrm{m} / \mathrm{sec})$ at $z=z_{t}$ and phase difference between $Q^{\prime}$ and $w^{\prime}$ at $z=z_{t} / 2$ (dashed line) for Kelvin waves of $s=1$ [upper] and mixed Rossby-gravity waves of $s=4$ [lower] in the model $S$ as a function of vertical wavelength (arrows indicate the position of maximum amplitude).

numbers.

The selectivity for periods of mixed Rossbygravity waves is very sharp, but the preferred periods are a little shorter than the observed ones. The selectivity for wavenumbers greatly differs from observations in the point that the amplitude monotonically increases with wavenumbers as is previously discussed in subsection 2-1 in relation to Eqs. (6)-(10). This discrepancy, however, may be removed by taking the influence of zonal wind shear into account. Let us consider the situation, for example, that an easterly flow prevails in the lower troposphere and a weak westerly in the upper troposphere such as the usual profile of zonal wind when mixed Rossby-gravity waves are dominant. The waves with shorter periods may be preferred in the lower layer, but, they can not have a positive equivalent depth in the upper layer. So such waves may not be prominent waves in that situation. This influence is more effective for large
KELVIN WAVE

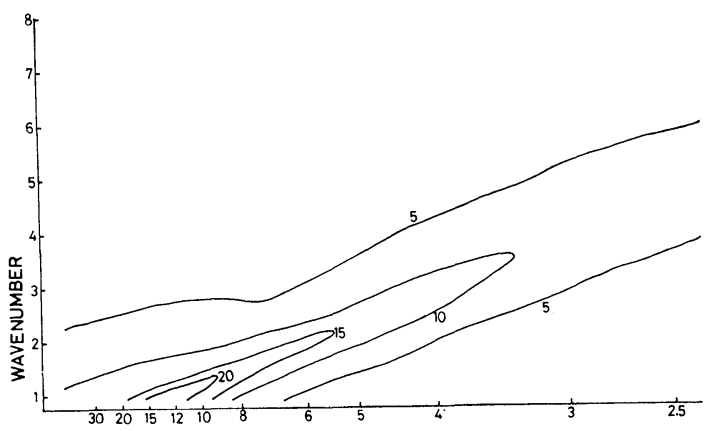

MIXED ROSSBY-GRAVITY WAVE

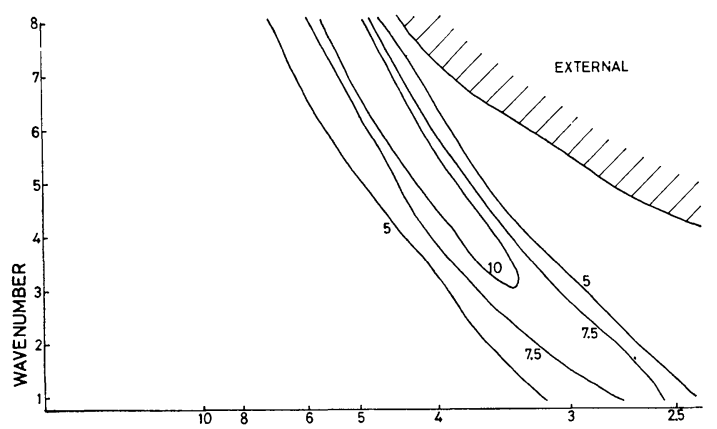

$n=1$ ROSSBY WAVE

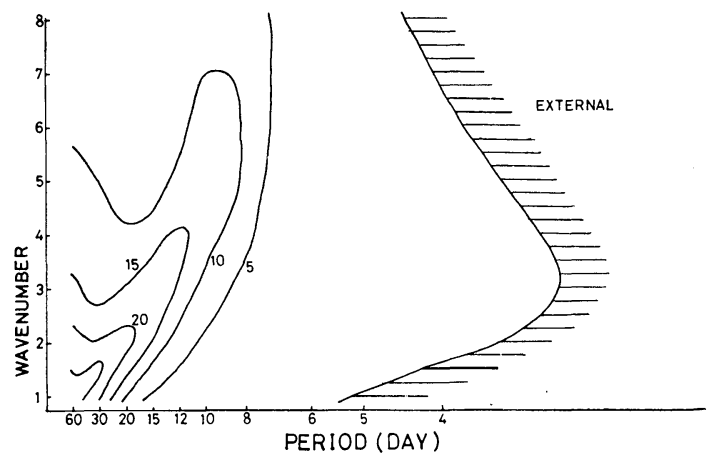

Fig. 4 RA at $z=z_{t}$ for Kelvin waves [upper], mixed Rossby-gravity waves [middle] and $n=1$ Rossby waves [lower] in the model $S(D=1 / 15$ days) as a function of wavenumber and period. Units are $\mathrm{m} / \mathrm{sec}$.

wavenumbers because the phase velocity of large wavenumber is slow and dimensionless Doppershifted period, $2 \Omega / \widehat{\omega}$, is easy to become smaller than wavenumbers (see Eq. (19)). Fig. 5 shows the critical zonal wind velocity at which mixed Rossby-gravity waves of given wavenumber and period transit from an internal type (lower part of the diagram) to an external type (upper part). It is concluded from this figure that there is an 


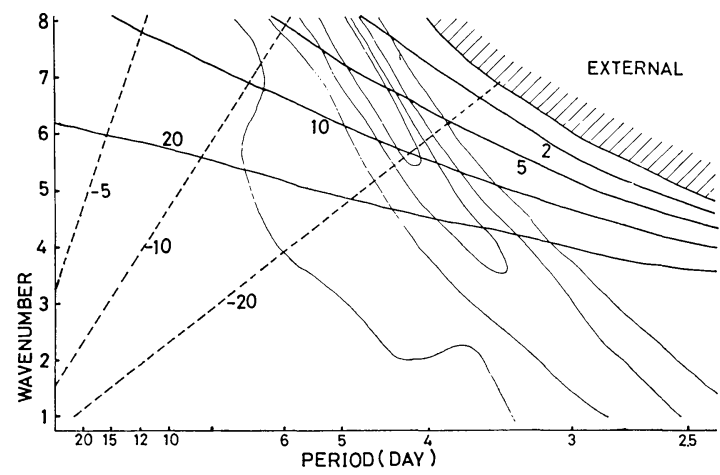

Fig. 5 Critical westerly wind (thick solid line) and critical easterly wind (dashed line) for the existence of mixed Rossbygravity waves as a function of wavenumber and period (Units are $\mathrm{m} / \mathrm{sec}$ ). For a given value of the zonal flow mixed Rossby-gravity waves can exist in the region below the curve. Thin solid line shows RA at $z=z_{t}$ in the model $S(D=0)$.

upper bound of wavenumber for the resonant waves to exist. The fact suggests that mixed Rossby-gravity waves with large wavenumbers can hardly exist for the realistic vertical distribution of zonal flow.

Regarding $n=1$ Rossby wave, the resonant wave amplitude SA exceeds that of Kelvin waves and mixed Rossby-gravity waves, since this mode has considerably longer periods than other waves with same equivalent depth (not shown). However, as the meridional scales are large with small $a_{1}$ 's, $n=1$ Rossby waves have comparable amplitude to Kelvin waves for realistic heating. The observed waves have the peak of wavenumber 1-2 with periods 7-15 days, which are shorter periods than the results of this model.

\section{Realistic model}

\section{3-1. Description of the model}

Investigation of the influences of horizontal distribution of forcing and vertical distribution of the zonal flow is the subject of this section. The system of equations with vertical shear flow is, however, non-separable with respect to $y$ and $z$. Solutions of the equation system which is nonseparable may be regarded as a composition of various wave modes approximately. Results of observations should be compared with the solution thus obtained, because they also include various wave modes without separation.
Let us consider the same model as Holton's (1972). We assume the zonal wind distribution as $\vec{u}(y, z)=U(z)\left(1-y^{2}\right)$. Adding advection terms due to the zonal flow to Eqs. (1)-(5) in $\lambda, \varphi, z$ coordinate system, and transforming them into the equation of a dependent variable $\Phi$ defined as $\Phi^{\prime}=\Phi(y, z) e^{i(\omega t+s \lambda)+z / 2 H}$, we obtain

$$
\begin{gathered}
\frac{\left(y^{2}-\widehat{\omega}^{2}\right)}{S}\left[\frac{\partial^{2}}{\partial z^{2}}-\frac{1}{4}-\sigma\left(\frac{\partial}{\partial z}+\frac{1}{2}\right)\right] \Phi \\
+\left(y^{2}-\widehat{\omega}^{2}\right) \frac{\partial}{\partial y}\left[\frac{1-y^{2}}{y^{2}-\hat{\omega}^{2}} \frac{\partial \Phi}{\partial y}\right] \\
+\left[\frac{s}{\hat{\omega}} \frac{y^{2}+\widehat{\omega}^{2}}{y^{2}-\hat{\omega}^{2}}-\frac{s^{2}}{1-y^{2}}\right] \Phi \\
=-\frac{i\left(y^{2}-\hat{\omega}^{2}\right)}{\hat{\omega}}\left(\frac{\partial}{\partial z}-\frac{1}{2}\right) \frac{Q}{S}
\end{gathered}
$$

where

$$
\begin{aligned}
& \widehat{\omega} \equiv \omega+\frac{s \bar{u}}{1-y^{2}}-i D, \\
& \sigma \equiv \frac{S}{\widehat{\omega}} \frac{d}{d z}\left(\frac{\widehat{\omega}}{S}\right), \\
& y \equiv \sin \varphi .
\end{aligned}
$$

This is a non-dimensional equation, with horizontal scale devided by the radius of the earth, $a$, vertical scale by scale height $H$, and time by the reciprocal of twice the angular velocity of the earth, $(2 \Omega)^{-1}$. Now we attempt to solve Eq. (51) numerically together with the following boundary conditions.

$$
w^{\prime}=0 \quad \text { at } z=0
$$

radiation condition at the upper boundary (40 $\mathrm{km}$ in practice).

$$
\begin{array}{cc}
\Phi=0 & \text { at } y=y_{p}\left(y_{p}=5 / 6 \text { in practice }\right), \\
{\left[\begin{array}{l}
\Phi=0 \\
\frac{\partial \Phi}{\partial y}=0
\end{array}\right.} & \text { at } y=0 \begin{array}{l}
\text { for antisymmetric mode } \\
\text { for symmetric mode. }
\end{array}
\end{array}
$$

The radiation condition is identical to Matsuno's method (1970). Grid intervals are $\Delta y=1 / 30$ and $\Delta z=1 \mathrm{~km} / \mathrm{H}$. The zonal winds $U(z)$ used in this model are shown in Fig. 6(a). The vertical distribution of the stability and the heating at $y=y_{0}$ are illustrated in Fig. 6(b). With regard to heating the same horizontal distribution of $Q^{\prime}$ as $q(y)$ in the previous section is assumed. The realistic asymmetric heating corresponding to the single ITCZ is obtained as the composition of symmetric and antisymmetric heating. Damping rate is $1 / 15$ days at any height.

As discussed previouly, we can anticipate three types of dominant waves to appear as shown in Table 1. Therefore computations are made only for wavenumbers with which the waves are ex- 

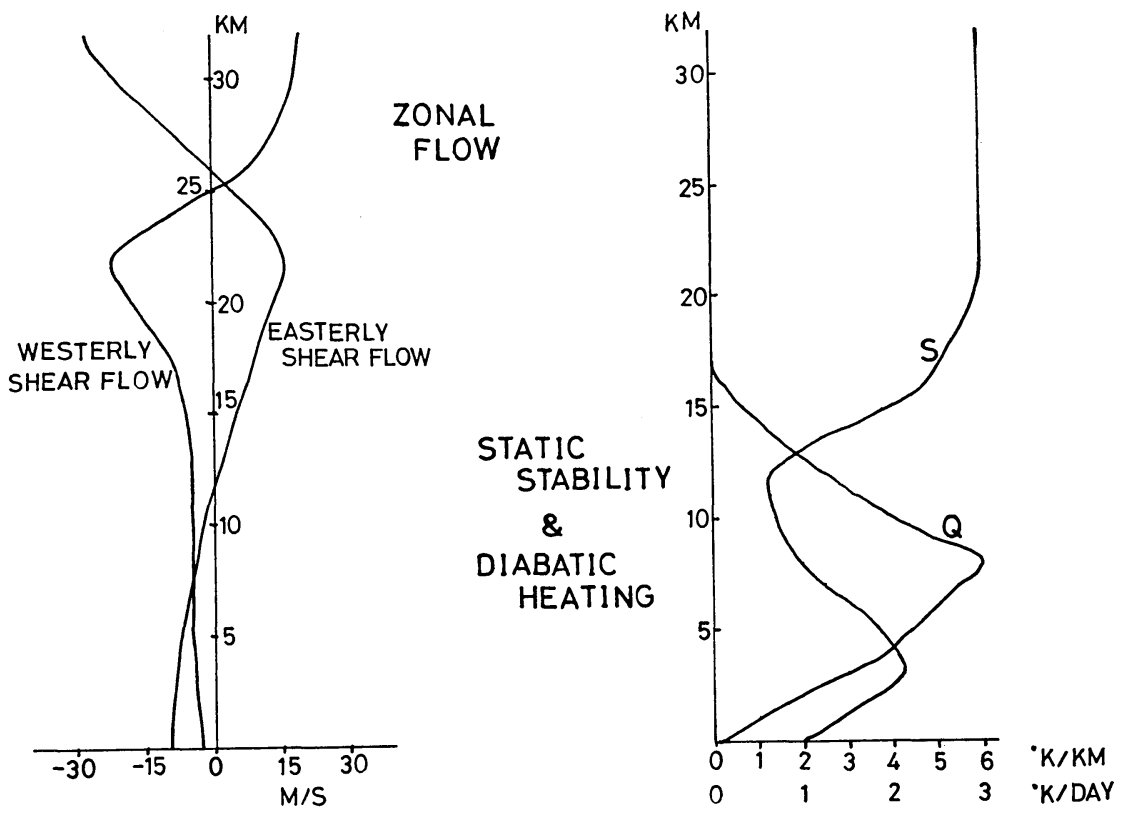

Fig. 6 Vertical distribution of (a) the mean zonal flow and (b) the static stability $S$ and the heating $Q^{\prime}$ at $y=y_{0}$ used in the model.

Table 1. Dominant wave modes classified according to moving direction and symmetry/ anti-symmetry with respect to the equator. $W$ represents the westerly shear flow and $E$ the easterly shear flow.

\begin{tabular}{c|c|c|c|c}
\hline & moving direction & $\begin{array}{l}\text { symmetry/antisymmetry } \\
\text { with respect to the } \\
\text { equator }\end{array}$ & identification & assumed wavenumbers \\
\hline 1 & eastward & symmetric & Kelvin wave & $\begin{array}{l}s=1,2 \text { for } W \text { and } \\
\text { for } E\end{array}$ \\
\hline 2 & westward & antisymmetirc & $\begin{array}{l}\text { mixed Rossbygravity } \\
\text { wave }\end{array}$ & $\begin{array}{l}s=2,3,4,5,6 \text { for } E \\
\text { and } s=4,5,6 \text { for } W\end{array}$ \\
\hline 3 & westward & symmetric & $n=1$ Rossby wave & $s=2$ for $E$ and $W$ \\
\hline
\end{tabular}

pected to be preferrable. The zonal flow with a westerly shear is assumed for eastward-moving symmetric mode and that with an easterly shear is chosen for westward-moving antisymmetric mode, unless otherwise stated.

Fig. 7 shows the horizontal structure of the disturbance caused by symmetric heating (Kelvin waves) and that by antisymmetric heating (mixed Rossby-gravity waves) at heights $16 \mathrm{~km}$ and $8 \mathrm{~km}$. At $8 \mathrm{~km}$, it seems that the basic wave modes are modified a little by the presence of other modes, while at the tropopause level $(z=16 \mathrm{~km})$ modification of the basic modes is little.

3-2. Selectivity for periods and wavenumbers

Figs. 8(a)-(c) represent the amplitude of zonal wind component as a function of height and period for Kelvin waves of $s=1$ and $s=2$ in the westerly shear flow, and the waves of $s=1$ in the easterly shear flow, respectively. It is found that the 20 day period wave for $s=1$ and the 15 day period wave for $s=2$ are dominant. These periods are longer than those of the normal mode model. This difference may be accounted for by the effects of the mean zonal wind (easterly wind in the troposphere), since the response of Kelvin wave is broad with respect to period. Since the peak of $s=1$ with $T=20$ days exists even for the easterly shear flow (Fig. 8(c)), we find that the response of the wave with such large zonal wavelength cannot be influenced so much by the upper 

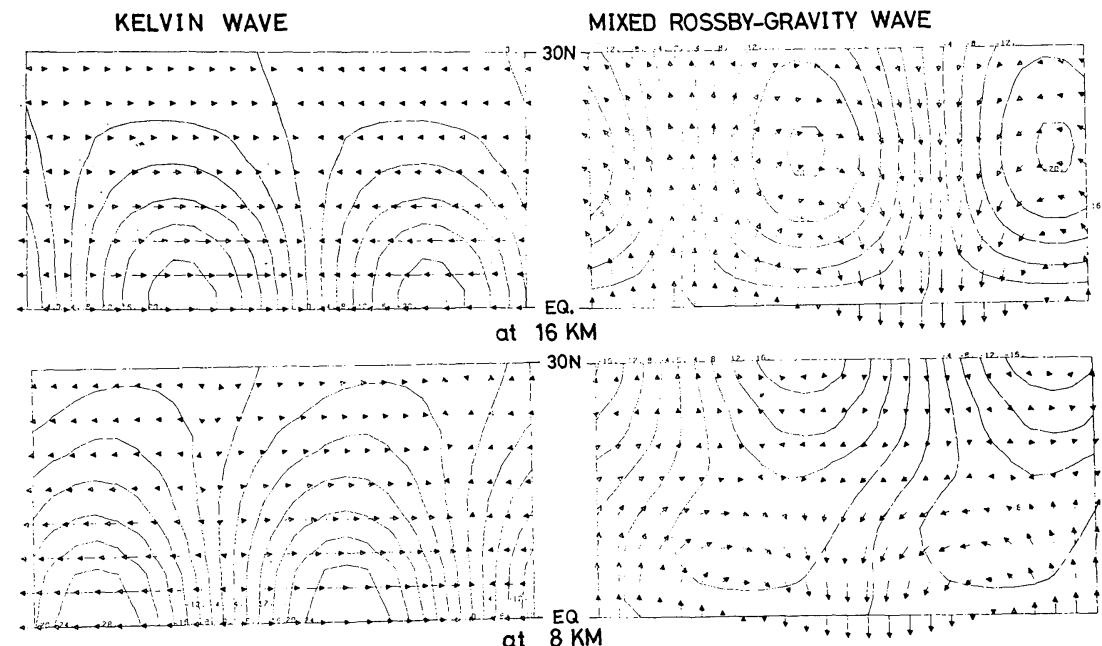

at $8 \mathrm{KM}$

Fig. 7 Horizontal structure of geopotential (solid line) and wind (arrow) at $16 \mathrm{~km}$ (upper) and $8 \mathrm{~km}$ (lower) for eastward-moving symmetric mode (Kelvin wave) of $s=1, T=15$ days and westward-moving antisymmetric mode (mixed Rossby-gravity wave) of $s=4, T=3.75$ days. (For mixed Rossby-gravity wave at $8 \mathrm{~km}$, wind velocity and geopotential are multiplied by a factor 2 ).

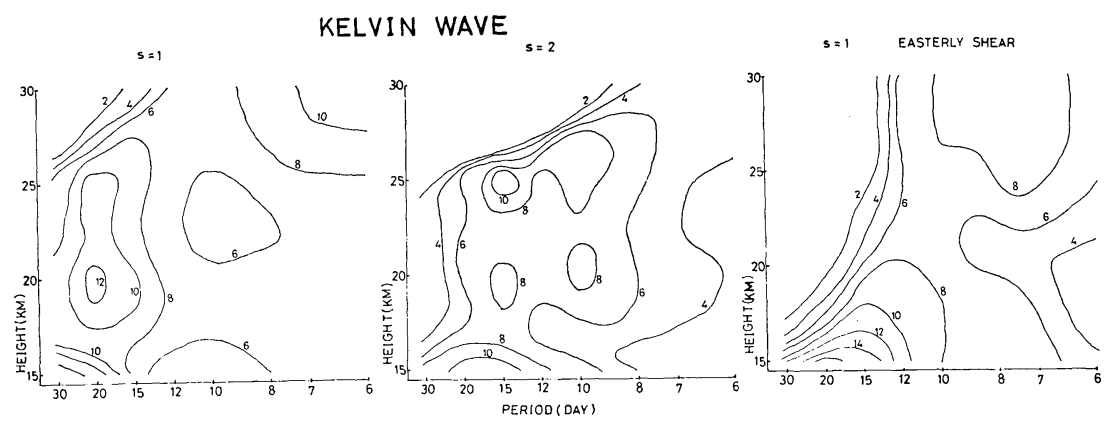

Fig. 8 Amplitude of zonal wind component over the equator for Kelvin waves of (a) $s=1$, (b) $s=2$ and (c) $s=1$ for the easterly shear flow as a function of height and period. Units are $\mathrm{m} / \mathrm{sec}$.

zonal flow.

Kelvin waves whose wavenumbers and periods give a constant product value have the same equivalent depth and phase speed. Since these two quantities are most important for determining wave amplitude, the two diagrams ( $8 \mathrm{a}$ and $8 \mathrm{~b}$ ) become more or less similar, when they are scaled properly. As the response is determined by equivalent depth, and the property of vertical propagation depends on phase speed, the predominant wave number in the upper troposphere and the stratosphere must be the same even if the mean zonal wind has a vertical shear.

Fig. 9(a)-(d) shows the amplitude of meridional wind component with height, for mixed Rossby- gravity waves of $s=3, s=4$ and $s=5$ in the easterly shear flow, and the waves of $s=4$ in the westerly shear flow. Figs. 10(a) and (b) represent the amplitude of the same wave at $16 \mathrm{~km}$ and the maximum amplitude in the stratosphere, respectively, as a function of wavenumber and period. It should be noted that the wavenumber with maximum amplitude at the tropopause is 5 and the amplitude of higher wavenumbers damps contrary to the normal mode model. This is due to the influence of mean zonal flow as discussed previously in connection with Fig. 5. Regarding mixed Rossby-gravity waves in the westerly shear flow, we obtain the results that the amplitude at the tropopause level is $5.1 \mathrm{~m} / \mathrm{sec}$ for $s=4, T=$ 


\section{MIXED ROSSBY-GRAVITY WAVE}
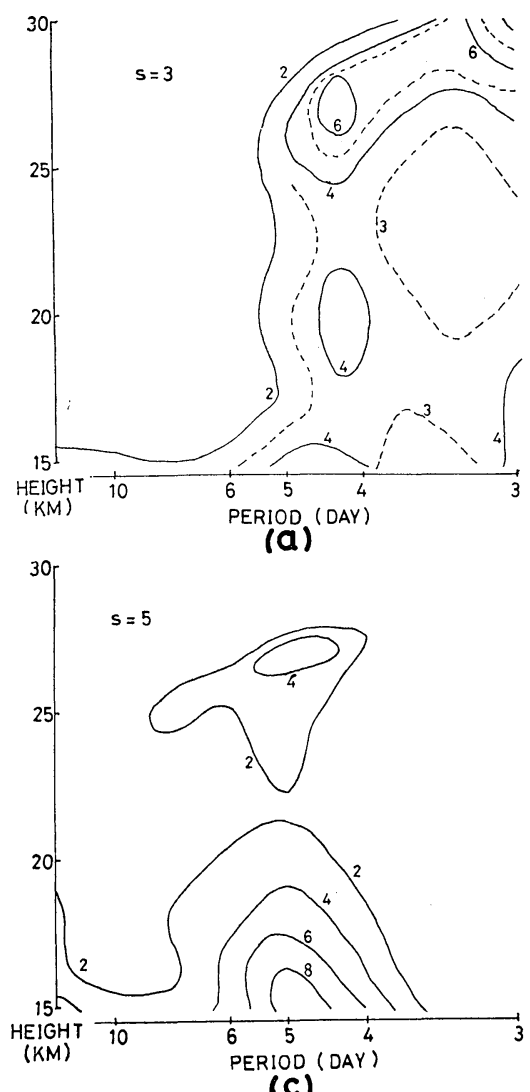

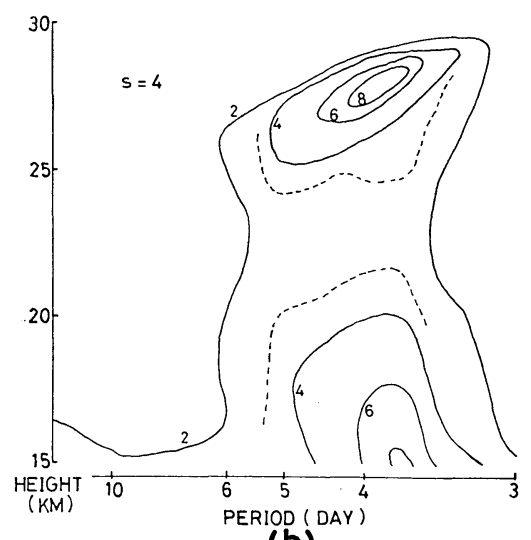

(b)

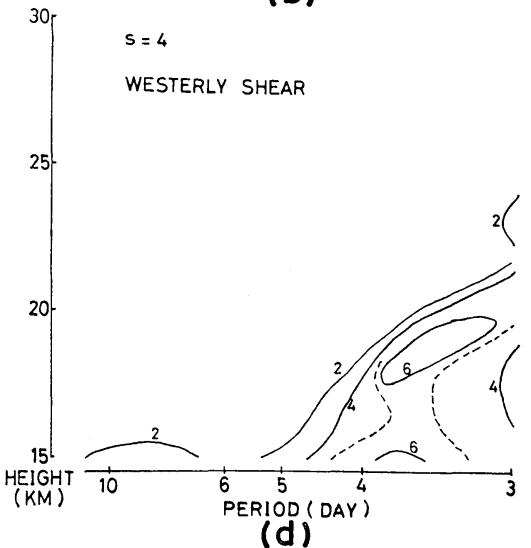

Fig. 9 Amplitude of meridional wind component over the equator for mixed Rossby-gravity waves of (a) $s=3$, (b) $s=4$, (c) $s=5$ and (d) $s=4$ for the westerly shear flow as a function of height and period. Units are $\mathrm{m} / \mathrm{sec}$.

3.75 days (Figs. 9 (d)), $0.7 \mathrm{~m} / \mathrm{sec}$ for $s=5, T=5.0$ days and $1.1 \mathrm{~m} / \mathrm{sec}$ for $s=6, T=6.0$ days (Figures are not shown here). Thus we find that the amplitude of wavenumber 5 and higher diminishes. Although the waves with large wavenumbers are prominent under some conditions at a level in the troposphere (figures not shown), it is inappropriate to mind the differences in view of the dominance throughout the troposphere. Through these computations, we may generally conclude that, even in the real zonal flow, mixed Rossby-gravity waves are predominant for wavenumber 4-5.

In the stratosphere, the dominant wavenumber is 4 which is different from wavenumber 5 dominant at $16 \mathrm{~km}$ level (Fig. 10(b)). This is because zonal shear flow gives great selectivity for wavenumbers (Lindzen, 1970).

As is shown in Fig. 9(b) and (d), the peak of $s=4$ in the westerly shear flow appears at the same period $T=3.75$ days as in the easterly shear flow, but the amplitude at the tropopause in the latter flow is larger than that in the former flow. It is considered that the waves in the easterly shear flow grow more resonantly by suffering from the reflection at the westerly wind in the lower stratosphere of the easterly shear flow.

The peak of $s=4$ exists at period 3.75 days which is longer than 3.3 days given by Hayashi (1976). This is mainly due to the effect of realistic latitudinal distribution of heating. However it is somewhat shorter than the observed periods, 4-5 days.

Fig. 11 illustrates the amplitude of zonal wind 
MIXED ROSSBY-GRAVITY WAVE $V$ at $16 \mathrm{KM}(\mathrm{M} / \mathrm{S})$

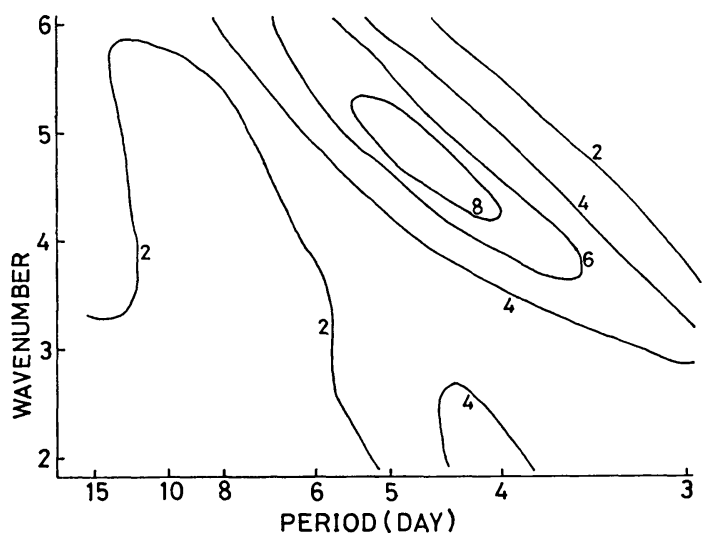

(a)

\section{MIXED ROSSBY-GRAVITY WAVE}

maximum $V$ in the stratosphere (M/S)

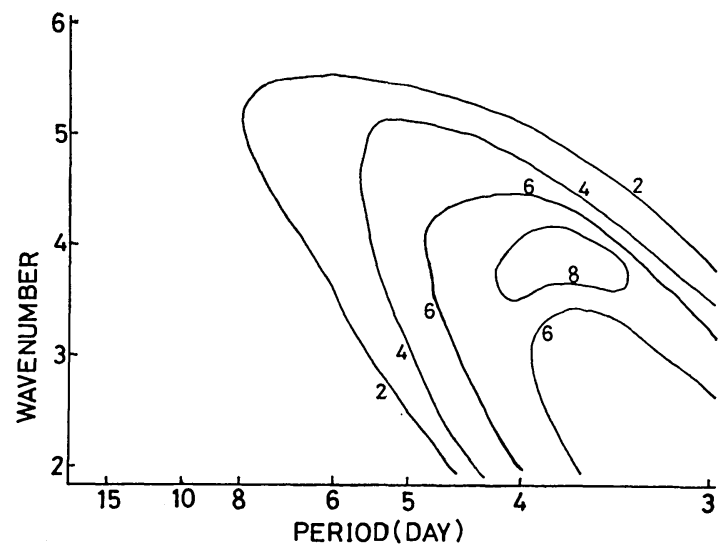

(b)

Fig. 10 (a) amplitude at $16 \mathrm{~km}$ and (b) maximum amplitude in the stratosphere of meridional wind component over the equator for mixed Rossby-gravity waves as a function of wavenumber and period. Units are $\mathrm{m} / \mathrm{sec}$.

component for $n=1$ Rossby waves with $s=2$ for the easterly shear flow. A distinct peak exists at the period of 12 days, which differs from the results of the normal mode model for Dopplershifted effects. This peak agrees with the result from GFDL general circulation model (Hayashi, 1974). For the westerly shear flow, $n=1$ Rossby waves do not have marked amplitude because they suffer from the absorption in the lower easterly.

\section{3-3. Wave structure}

Let us consider the phase relationship between

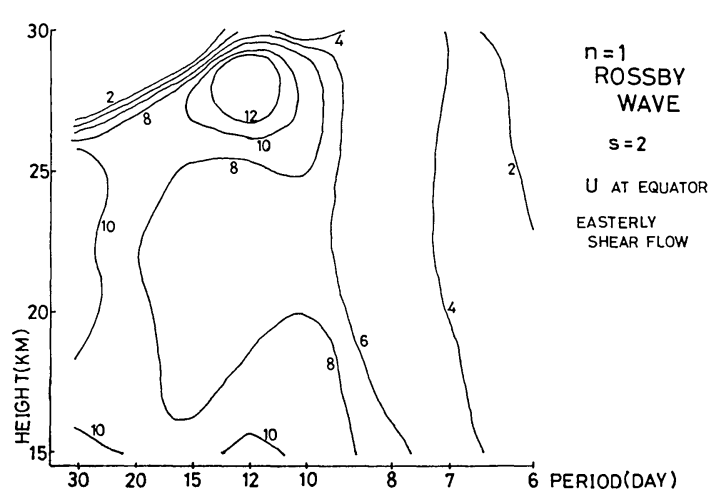

Fig. 11 Amplitude of zonal wind component over the equator for $n=1$ Rossby waves of $s=2$ as a function of height and period. Units are $\mathrm{m} / \mathrm{sec}$.

$Q^{\prime}$ and $w^{\prime}$ of resonant waves. In order to avoid complexity arising from the influence of the mean zonal flow, $U(z)=0$ is assumed. In this case the resonant Kelvin wave is $T=15$ days for $s=1$ and the resonant mixed Rossby-gravity wave is $T=$ 3.75 days for $s=4$. Even if the effect of zonal flow is included, the essential features of the structure of waves with maximum response are not changed in the troposphere.

Fig. 12 (Fig. 14) shows distributions of the amplitudes and phase angles of various variables in the meridional direction at $8 \mathrm{~km}$ height and Fig. 13 (Fig. 15) shows the phase variation in the vertical direction at latitudes $5.7^{\circ}$ and $0^{\circ}\left(11.5^{\circ}\right)$ for Kelvin wave (mixed Rossby-gravity wave), respectively. The latitude $5.7^{\circ}$ is selected as that of the maximum heating and $0^{\circ}\left(11.5^{\circ}\right)$ as the latitude where the vertical motion $w^{\prime}$ of the basic mode, i.e., pure Kelvin wave (pure mixed Rossbygravity wave), must have the maximum magnitude. It is remarkable that $Q^{\prime}$ and $w^{\prime}$ are in phase and $w^{\prime}$ has maximum amplitude at $5.7^{\circ}$. On the other hand, they are in quadrature and $w^{\prime}$-amplitude is small at $0^{\circ}\left(11.5^{\circ}\right)$ in this model. Then the phase variation of $w^{\prime}$ with latitude is fairly large. This means that other modes coexist together with the basic wave mode, because the basic mode does not show such strong variation of phase with latitude. Note that this has been pointed out in relation to the horizontal structure in Fig. 7.

Since the coexisting modes disturb considerably the $w^{\prime}$-field only, it is conjectured that they are short vertical wavelength modes, i.e., gravity wave modes. The coexistence of short vertical wavelength modes can also be explained as fol- 

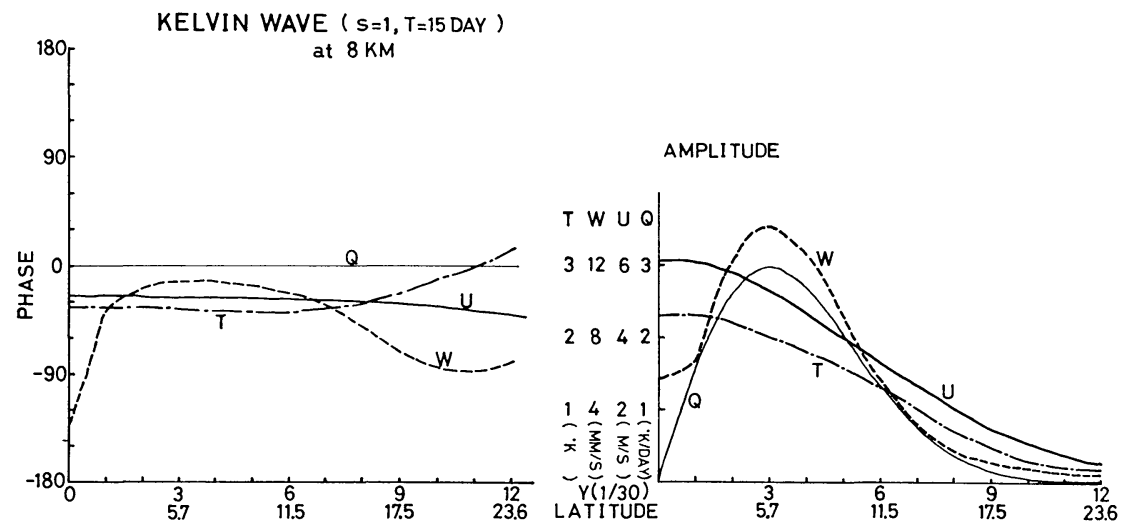

Fig. 12 Latitudinal profile of amplitude and phase angle of $w^{\prime}, u^{\prime}, T^{\prime}$ and $Q^{\prime}$ at $8 \mathrm{~km}$ for the Kelvin wave with $s=1, T=15$ days.

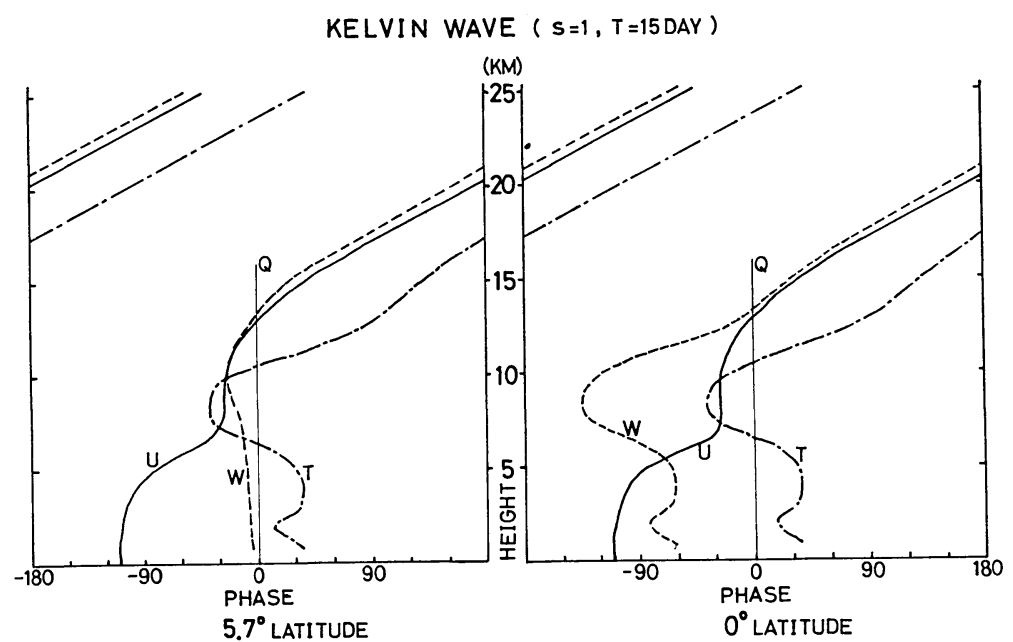

Fig. 13 Vertical profile of phase angle of $w^{\prime}, u^{\prime}, T^{\prime}$ and $Q^{\prime}$ at $5.7^{\circ}$ latitude (left) and $0^{\circ}$ latitude (right) for the Kelvin wave with $s=1, T=15$ days.
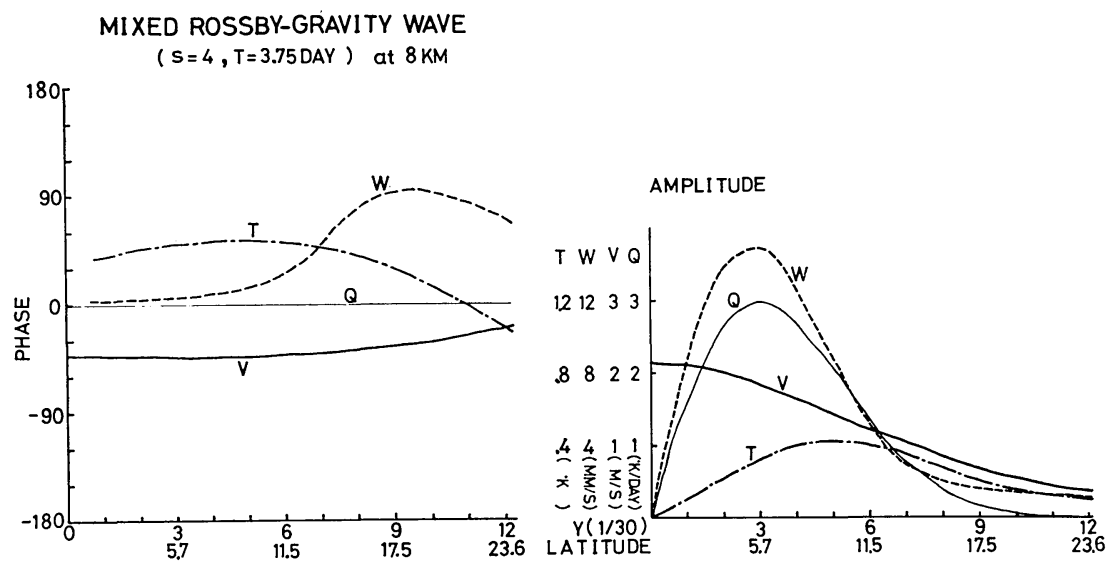

Fig. 14 Same as Fig. 12 except for the mixed Rossby-gravity wave with $s=4, T=3.75$ days. 


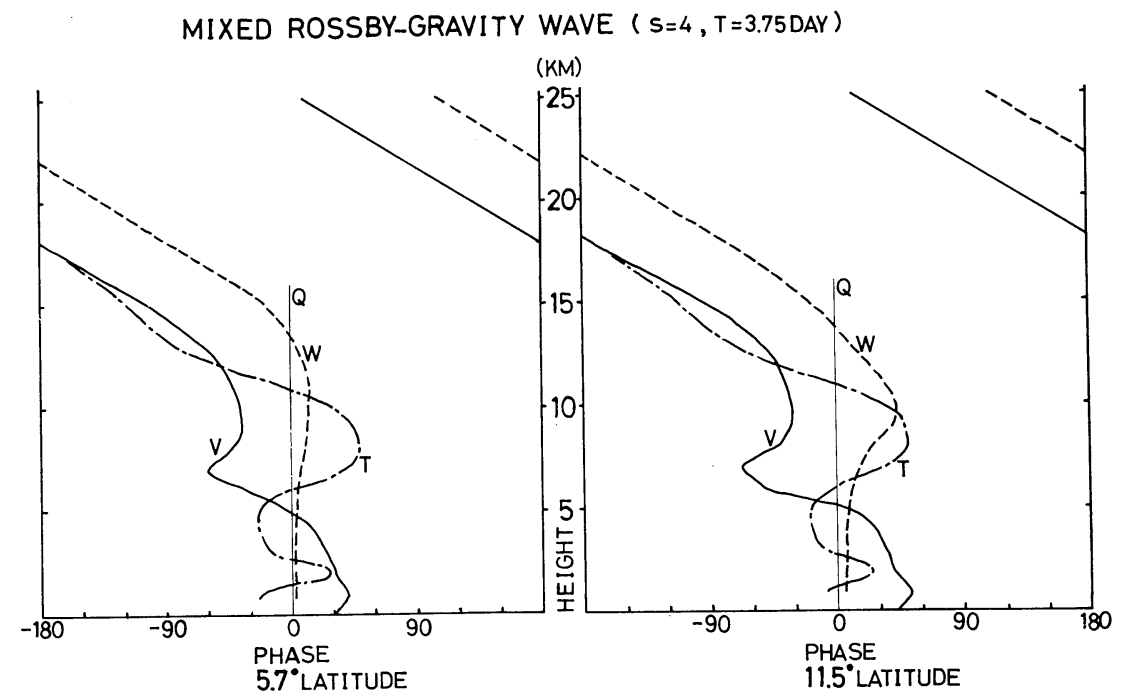

Fig. 15 Same as Fig. 13 except at $5.7^{\circ}$ latitude (left) and $11.5^{\circ}$ latitude (right) for the mixed Rossby-gravity wave with $s=4, T=3.75$ days.

lows. As the latitude where $T^{\prime}$ and $w^{\prime}$ of the resonant basic mode have maximum amplitude differs from the latitude of maximum $Q^{\prime}$, other modes which have maximum $w^{\prime}$ near the latitude of maximum $Q^{\prime}$ must exist in order to satisfy Eq. (5). These modes must have small equivalent depths, because the latitude of maximum $Q^{\prime}$ is closer to the equator.

It is found from (41) that the modes with short vertical wavelength (large $\lambda$ ) satisfy the inphase relation between $Q^{\prime}$ and $w^{\prime}$ : As the second term in the bracket dominates the first term because of $1 \gg M / \lambda$, and as $\lambda^{2}-M^{2}>0$, the phase of $w_{1}(z)$ becomes near $0^{\circ}$.

On the other hand, in the stratosphere the phase variation of $w^{\prime}$ axis in the meridional direction is small because such gravity waves are not resonant and only the forced term, i.e., $\sin M z$ in (41), contributes to the large amplitude in the troposphere, which vanishes in the stratosphere. Thus pure basic modes can be seen in the stratosphere.

Even when the heating is a realistic asymmetric heating, in-phase relationship between $Q^{\prime}$ and $w^{\prime}$ holds, because $w^{\prime}$ almost balances with $Q^{\prime}$ in Eq. (5) near the latitude where the heating has its maximum. Therefore, in the composition of symmetric and antisymmetric models, composite $w^{\prime}$ has large amplitude and $w^{\prime}$ becomes in phase with $Q^{\prime}$ at the latitudes corresponding to the ITCZ.

Concerning the vertical structure of wind and temperature, however, some questions arise from the careful inspection of Figs. 13 and 15. The phase of perturbation wind in the troposphere is considerably different from the observed one. In observed mixed Rossby-gravity waves, the constant phase axis of $v^{\prime}$ inclines eastward with height in the middle and lower troposphere, and westward in the upper troposphere and the stratosphere (e.g., Nitta, 1972). However, in the present model it generally inclines westward even in the lower troposphere, although the energy flux $\overline{\Phi^{\prime} w^{\prime}}$ associated with the wave is downward from the middle to the lower troposphere. For Kelvin waves, the observed constant phase axis of $u^{\prime}$ inclines westward in the lower layer and eastward in the upper layer (e.g., Nitta, 1972), whereas in this model it inclines eastward even in the lower layer. The vertical structure of temperature for both wave modes also differs from observations. Such vertical structure does not vary even if the cooling effect in the mixed layer and/ or the effect of surface friction are incorporated (not shown). As mentioned above, the structure of the selected Kelvin waves in a shear zonal flow, with $T=20$ days for $s=1$, is similar to that of $T=15$ days without shear. Then it can be concluded that, although in Holton's (1973) model, the both effects (resonance to forcing and vertical propagatability) are included, the selected waves are essentially resonant waves, so that the vertical structure may not coincide with the observed one.

Moreover, if the position of ITCZ moves to north, the phase relation between $Q^{\prime}$ and $w^{\prime}$ 


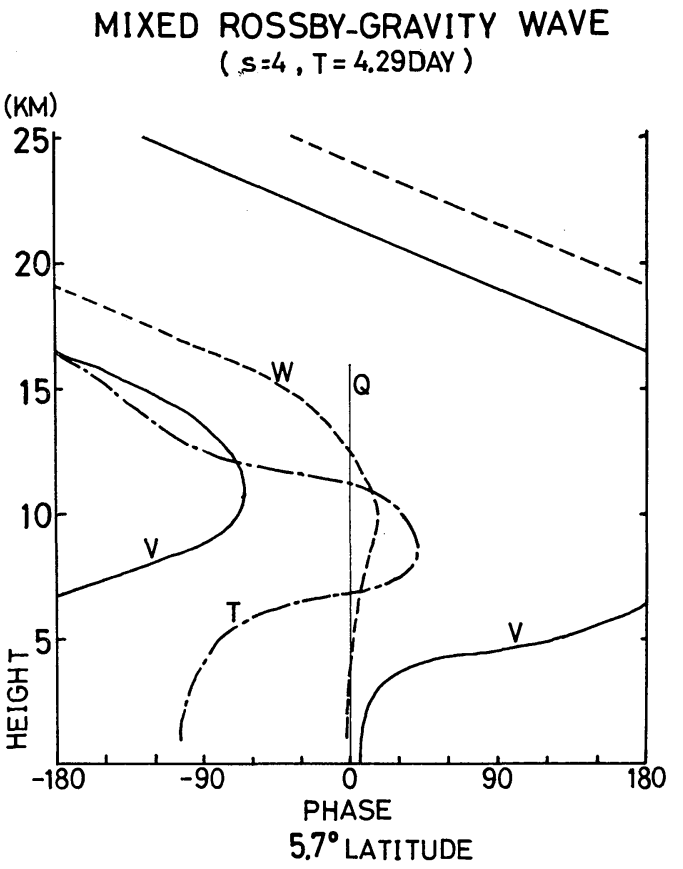

Fig. 16 Same as Fig. 13 except at $5.7^{\circ}$ latitude for the mixed Rossby-gravity wave with $s=4, T=4.29$ days.

changes from in-phase to in quadrature, since gravity waves with short vertical scale are hard to be excited. As a matter of fact, when the heating has maximum amplitude at $11.5^{\circ}$, the phase difference between $Q^{\prime}$ and $w^{\prime}$ of the mixed Rossby-gravity wave with $s=4, T=3.75$ days is about $30^{\circ}$ at $10 \mathrm{~km}$. This is contrast to the result from GFDL model, in which $Q^{\prime}$ and $w^{\prime}$ are in phase although the latitudes where the heating is maximum are $10^{\circ} \sim 15^{\circ} \mathrm{N}$ (Hayashi, 1974).

Finally, it should be noted that there exists a wave whose structure coincides with observed one for a non-resonant period. Fig. 16 shows the vertical structure of mixed Rossby-gravity wave with $s=4, T=4.29$ days, which are same as those of observed waves. In contrast to Fig. 15, the agreement of the wave structure with observations is quite well.

Through the computations it may be fair to say that there still remain some problems to simulate the observed characteristics of waves in a framework of the present model. Thus we conclude that it is unlikely to identify the observed waves merely with the resonant waves by thermal forcing. The fact that the vertical structure of a non-resonant wave resembles the observed one suggests that other effects should be taken into account.

\section{Conclusions and remarks}

A theoretical examination of the response of equatorial wave disturbances to thermal forcing was made. The results obtained are summarized as follows.

1) In the normal mode model with no mean zonal flow, the resonance occurs when the vertical wavelength in the troposphere coincides with twice the forcing scale. Among the resonant waves, the wave with the lowest frequency has the largest amplitude. Therefore, Kelvin waves attain their maximum response at wavenumber 1 similar to observations, whereas mixed Rossbygravity waves dominate at large wavenumbers contrary to observations. Heating $Q^{\prime}$ and vertical motion $w^{\prime}$ of the resonant waves are in quadrature. These results reconfirm what have been shown by Hayashi (1976) and Chang (1976).

2) Even if the vertical distribution of heating is changed, the phase relation between $Q^{\prime}$ and $w^{\prime}$ of the resonant waves does not change.

3) If we treat the realistic meridional distribution of heating as the projection on normal modes, the vertical wavelength with maximum response becomes shorter than twice the forcing scale. Therefore, the phase difference between $Q^{\prime}$ and $w^{\prime}$ approaches to $0^{\circ}$ and the predominant period becomes longer. However, degree of this variation is too small to explain the observed waves.

4) If we permit the existence of other modes together with the basic mode, $Q^{\prime}$ and $w^{\prime}$ become in phase because of the effect of gravity waves, which, however, do not disturb substantially the structure of wind and geopotential of the basic mode.

5) The influence of zonal shear flow suppresses the resonant mixed Rossby-gravity waves with higher wavenumbers, so mixed Rossbygravity waves of wavenumber 4-5 become most dominant even in the troposphere.

6) The waves with maximum response, however, differ from the observed waves in the vertical structure of wind and temperature in the troposphere, in either case with and without a vertical shear.

Despite of the agreement with observations in items 4) and 5) discrepancies between the observed characteristics and computations in the vertical structure of wind and temperature and in the predominant period of mixed Rossbygravity waves cannot permit the interpretation of the observed waves merely as the resonant 
waves by thermal forcing. The response to a $R$ thermal forcing can be understood as the reflec- $C$ tion of the projection coefficient of forcing on normal mode, with a little change by the static stability variation with height. From such response the waves with the short vertical wavelength and the vertical structure as observed cannot be selected. The selection of the particular vertical mode in the tropics from various vertical modes in mid-latitudes cannot also be expected from a lateral forcing theory of the dry tropical atmosphere. These suggest the importance of the interaction between wave and cumulus convection. Therefore the extended version of wavecumulus interaction will be required in future to have a deeper insight into the nature of equatorial waves.

\section{Acknowledgements}

The auther expresses his hearty thanks to Prof. R. Yamamoto for his encouragements throughout this work. The auther is deeply indebted to Prof. I. Hirota for his discussions and critical reading of the manuscript. He also wishes to thanks Prof. T. Matsuno of Geophysical Institute, Tokyo University, for many stimulative suggestions and Dr. Y. Hayashi of GFDL, Princeton University, for his valuable comments. Thanks are also due to Miss S. Yanabu for typing the manuscript.

\section{Appendix}

List of Symbols

\begin{tabular}{|c|c|}
\hline$t$ & time \\
\hline$x, y$ & $\begin{array}{l}\text { zonal and meridional coordinates in } \\
\text { Cartesian coordinate (in Section 2) }\end{array}$ \\
\hline$\lambda, \varphi$ & $\begin{array}{l}\text { zonal and meridional coordinates } \\
\text { spherical coordinate (in Section 3) }\end{array}$ \\
\hline$z$ & $\begin{array}{l}\log \text { pressure vertical coordinate } \\
\left(=-H \ln p / p_{o}\right)\end{array}$ \\
\hline$p$ & pressure \\
\hline$p_{0}$ & reference pressure $(=1,000 \mathrm{mb})$ \\
\hline$u^{\prime}, v^{\prime}$ & eastward and northward velocity \\
\hline$w^{\prime}$ & $\begin{array}{l}\text { "vertical velocity" in log pressure coor- } \\
\text { dinate }(=d z / d t)\end{array}$ \\
\hline$\Phi^{\prime}$ & geopotential height \\
\hline$T^{\prime}$ & temperature \\
\hline$Q^{\prime}$ & diabatic heating rate \\
\hline$\omega$ & frequency \\
\hline$s$ & integer wavenumber \\
\hline$k$ & $\begin{array}{l}\text { wavenumber }(=s / \text { the radius of the } \\
\text { earth })\end{array}$ \\
\hline$h$ & equivalent depth \\
\hline$H$ & $\begin{array}{l}\text { le height }(=7.5 \mathrm{~km} \text { in Section } 2,7 \\
\text { Section } 3)\end{array}$ \\
\hline & tion by gravity \\
\hline
\end{tabular}

gas constant

specific heat at constant pressure

$R / C_{p}$

Rayleigh friction and Newtonian cooling rate $(=1 / 15$ days or 0$)$

static stability

Rossby parameter

angular velocity of the earth

radius of the earth

\section{References}

Chang, C. P., 1976: Forcing of stratospheric Kelvin waves by tropospheric heat sources. J. Atmos. Sci., 33, 740-744.

Hayashi, Y., 1970: A theory of large-scale equatorial waves generated by condensation heat and accelerating the zonal wind. J. Meteor. Soc. Japan, 48, 140-160.

, 1974: Spectral analysis of tropical disturbances appearing in a GFDL general circulation model. J. Atmos. Sci., 31, 180-218.

, 1976: Non-singular resonance of equatorial waves under the radiation condition. $J$. Atmos. Sci., 33, 183-201.

Holton, J. R., 1972: Waves in the equatorial stratosphere generated by tropospheric heat sources. J. Atmos. Sci., 29, 368-375.

, 1973: On the frequency distribution of atmospheric Kelvin waves. J. Atmos. Sci., 30, 499-501.

- 1975: The dynamic meteorology of the stratosphere and mesospher. Amer. Meteor. Soc., $216 \mathrm{pp}$.

and R. S. Lindzen, 1968: A note on "Kelvin" waves in the atmosphere. Mon. Wea. Rev., 96, 385-386.

Kuo, H.-L., 1975: Instability theory of large-scale disturbances in the tropics. J. Atmos. Sci., 32, 2229-2245.

Lamb, V. R., 1973: The response of a tropical atmosphere to middle latitude forcing. Ph.D. thesis, University of California, Los Angeles.

Lindzen, R. S., 1967: Planetary waves on beta planes. Mon. Wea. Rev., 95, 441-451.

1970: Internal equatorial planetary-scale waves in shear flow. J. Atmos. Sci., 22, 394407.

-, 1974: Wave-CISK in the tropics. J. Atmos. Sci., 31, 156-179.

- and T. Matsuno, 1968: On the nature of large-scale wave disturbances in the equatorial lower stratosphere. J. Meteor. Soc. Japan, 46, 215-221.

Mak, M. K., 1969: Laterally driven stochastic motions in the tropics. J. Atmos. Sci., 26, 41-64.

Maruyama, T., 1967: Large-scale disturbances in the equatorial lower stratosphere. J. Meteor. Soc. Japan, 45, 391-408. 
Matsuno, T., 1966: Quasi-geostrophic motions in the equatorial area. J. Meteor. Soc. Japan, 44, 2543.

1970: Vertical propagation of stationary planetary waves in the winter Northern Hemisphere. J. Atmos. Sci., 27, 871-883.

Nitta, Tsuyoshi, 1972: Structure of wave disturbances over the Marshall Islands during the years of 1956 and 1958. J. Meteor. Soc. Japan, 50, 85-103.

Odo, K., 1976: An analysis of stratospheric wave disturbances over the tropical Pacific. J. Meteor. Soc. Japan, 54, 351-360.

Reed, R. J. and E. E. Recker, 1971: Structure and properties of synoptic scale wave disturbances in the equatorial western Pacific. J. Atmos. Sci., 28,
1117-1133.

Rosenthal, S. L., 1965: Some preliminary theoreticai considerations of tropospheric wave motions in equatorial latitudes. Mon. Wea. Rev., 93, 605612.

Tsay, C. Y., 1974: Analysis of large-scale wave disturbances in the tropics simulated by an NCAR global circulation model. J. Atmos. Sci., 31, 330-339.

Wallace, J. M. and V. E. Kousky, 1968: Observational evidence of Kelvin waves in the tropical stratosphere. J. Atmos. Sci., 25, 900-907.

Yanai, M. and T. Maruyama, 1966: Stratospheric wave disturbances propagating over the equatorial Pacific. J. Meteor. Soc. Japan, 44, 291-294.

\title{
熱的強制に対する赤道波の応答
}

\author{
伊 藤 久 徳 \\ (京都大学・地球物理学教室)
}

熱的強制による成層圈赤道波の応答特性を理論的に調べた。その際考えらる多くの効果, 特に heating の緯度分 布や帯状流の鉛直シアーを考慮に入れた。normal mode モデルに括いては, 熱的強制理論の欠点は, ほとんど改善 されなかったが，現実的な三次元モデルにおいては，次のような結果が得られた。

計算による水平構造から, 卓越モードとして Kelvin 波, 混合 Rosbky 重力波, $n=1$ Rossby 波が同定でき, 重 力波は卓越しないことがわかる。しかし，この重力波の混在によって，ITCZ 付近に最大值を持つょうな現実的な heating の緯度分布を含むモデルは, normal mode モデルの弱点であった heating と上昇流の間の約 $90^{\circ} の$ 位相差 を大きく変え, 実測される位相の一致を示す。また, 帯状流のシアーの影響によって, 混合 Rossby 重力波は大き な波数で卓越せず, 実測されるよう飞波数 4-5 で最大の応答を持つ。

しかし, 実測と比較して, その共鳴波の鉛直波長が少し長すぎ, 従ってその周期が少し短かいといら normal mode モデルの欠点は, 現実的な heating の効果により多少改善されるが，本質的には依然としてそのまま残され る。更に卓越波の風速成分と温度の鉛直構造もまた，対流圈では，実測されるものとは異った様相を示す。

これらの結果はいくつかの実測の特徵を説明はするが,な打実測される赤道波を単に熱的強制による共鳴波として だけでは解釈できないことを示している。 